\title{
DETERMINATION OF TRAFFIC PATTERNS ON URBAN ROADS
}

Traffic volume indicates the use and the capacity of road infrastructure. In traffic engineering the traffic volume is generally stated as so-called Annual Average Daily Traffic (abbreviated as AADT), which can be determined from a short-time traffic survey according to the TP 189 methodology. The issue of AADT determination is in fact simplified on the urban roads where we can find types of traffic patterns different from those dealt with in theTP 189 methology.

The introductory part of the paper deals with the theory of determination of traffic volumes and the theory of traffic flow. The aim of the article is to demonstrate traffic patterns on specific urban roads determined by the authors according to the idea that different types of traffic flows on urban roads within the different urban areas may be found. The paper deals with the issue of factors influencing the traffic flows within the city as well.

Keywords: Traffic Flow, Annual Average Daily Traffic, Traffic Patterns, Constant Time Headway Model, Urban Road Transport Network, Passenger Car Unit.

\section{Introduction}

The city area itself consists of several multifunctional areas interconnected by transport network. Each city area generates a different number of routes of the transport network users (city residents, employees, etc.). The number and nature of routes are significantly given by the function of the area and the activities of the local population. Moreover, there is transit traffic which is in certain areas of the city involved in the total traffic volume on transit urban roads. City transport system (network) can be therefore considered as a "live" network where the final traffic volumes on the road sections between each city areas are affected by a wide range of factors. In the following lines of the article the authors attempt to outline the issue of traffic flow and define some of the factors influencing the size of the traffic flow on urban roads.

Most methodological tools for calculating resulting traffic volumes on roads from a short-term traffic survey use the road categories and the sets of coefficients which are determined for such road categories (according to the Technical Conditions TP 189) [1]. The methodology is partially based on the german manual HBS (in German: Handbuch fur die Bemessung von Strassenverkehrsanlagen) [2]. The methodology contained in TP 189 sets out the coefficients (traffic variations within the day, week and month of a year) which are determined from long-term measurements conducted on different categories of roads in the Czech Republic. By using these coefficients it is possible to determine Average Annual Daily Traffic volume (AADT), Designed Hourly Volume (DHV) or other determinative traffic engineering outputs. We can determine AADT from short-time traffic measurement according to [1]:

$R P D I_{x}=I_{m} \cdot k_{m, d} \cdot k_{d, t} \cdot k_{t, R P D I}$,

where: $R P D I_{x}$ - Annual Average Daily Traffic to be determined (AADT) [cars/24 hours within day], $I_{m}$ - traffic volume of a given type of vehicle identified during the traffic survey [cars/traffic survey duration], $k_{m, d}$ - conversion coefficient of traffic volume acquired during the survey to daily traffic volume [-], $k_{d, t}$ - conversion coefficient of daily traffic volume within the day of survey to average daily traffic volume within the week (all seven days in a week) [-], $k_{t, R P D I}$ - conversion coefficient of weekly average daily traffic volumes to an annual average daily traffic volume [-].

In fact, in relation to urban traffic the sets of conversion coefficients included in TP 189 are set for road categories determined according to the categorization of the Roads Act (transit roads of I., II. or III. class going through the city, urban local roads or urban local roads connecting larger commercial zones) [3]. Especially on urban roads we can determine other

\footnotetext{
* ${ }^{1}$ Ladislav Bartuska, ${ }^{1}$ Karel Jerabek, ${ }^{2}$ Li Chenguang

${ }^{1}$ The Institute of Technology and Business in Ceske Budejovice, Faculty of Technology, Department of Transport and Logistics, Czech Republic ${ }^{2}$ North China University of Technology, School of Economics and Management, Business Management Department,

The People's Republic of China

E-mail: bartuska@mail.vstecb.cz
} 
traffic patterns which have significant influence on the final AADT and which are discussed in this paper.

Some methodological approaches are based on functional classification of the area within the city or town (spatial plans) where the area defined by the function is for simplification considered as monofunctional. In the real environment, however, city areas or area categories according to the spatial plan are more or less multifunctional and other factors having a significant influence on the resulting traffic intensity on urban roads should be taken into consideration [4].

\section{Factors influencing the traffic volumes in urban areas}

In general, especially the kind and time of day, weather, events, road works and accidents have an impact on the traffic volume in a given area (or on demand for transport). In the city there is a specific issue, since there is variation of the concentration of travel origins and travel destinations of transport network users - it is necessary to search for factors which more or less affect the traffic flow and its size on a given section of the road within the city.

One of the factors influencing the number of trips in a given area of the city should be the main urban area function (for example, the area function according to the spatial plan). The city is usually divided into individual mono-functional or multi-functional areas.

Traffic solutions and transport services within areas, routing of transport infrastructure and organization of transport systems, technical parameters of communications, capacity of intersections, parking areas and others should be designed in accordance with specific conditions in the urban area. Broader and local relations within the area should be respected and solved at different levels. It is alwavs necessarv to take into account not only the overall structure of the urban area, but also all the specific aspects (present and future) that may have, in the circumstances, an influence on the behavior of transport, namely the volume of generated traffic and modal split of transport [5]. This is essentially a composition and arrangement of individual parts of the urban structure and a varied range of specific factors, mainly qualitative. Some of these potential factors are determined in Table 1 [4].

Taking into account the positive or negative impact of the various conditions of urban areas and other specific factors is an important prerequisite for the proper assessment and design of the effective transport system. It is more than appropriate to consider these factors when determining the final traffic volumes on a given section of urban road in the sense of comparing these volumes to the road infrastructure capacity.

\section{Traffic flow theory}

For the modeling and simulation of traffic flow (traffic stream) on road network sections different models are used, of which the best known are probably the Car Following Model (CFM), the Optimal Velocity Model (OVM), or the Intelligent Driver Model (IDM). These microscopic models reflect reality more accurately than macroscopic stationary models [4].

For the purposes of this article the authors demonstrate the macroscopic approach to the traffic flow theory also known as the constant time headway $(\mathrm{CTH})$ model. When applying this model the idea from the field of traffic safety is considered, i.e. that each reference vehicle keeps a constant distance from the vehicle ahead. Based on this model the characteristics of the traffic flow can be generally determined: velocity $v$, density $k$, and traffic volume $q$ (flow).

Potential factors affecting the traffic volumes in relation to urban area

Table 1

\begin{tabular}{|c|c|c|}
\hline Urban level & Structure & Specific factors \\
\hline $\begin{array}{l}\text { - The nature of settlement structure; } \\
\text { - the position of given area within the } \\
\text { settlement structure; } \\
\text { - area in the central part of the city; } \\
\text { - area in suburban part of city; } \\
\text { - catchment area for other part of the city; } \\
\text { - the microstructure of given area, etc. }\end{array}$ & $\begin{array}{l}\text { - The spatial form of the transport system; } \\
\text { - the spatial arrangement of buildings; } \\
\text { - terrain configuration; } \\
\text { - functional layout of area; } \\
\text { - } \text { area accessibility; } \\
\text { - mono- or multi-functional area; } \\
\text { - interactions between functional areas; } \\
\text { - interconnection of transport systems, etc. }\end{array}$ & $\begin{array}{l}\text { - The importance and attractiveness given } \\
\text { area; } \\
\text { - attractiveness of the area location for } \\
\text { a given function; } \\
\text { - standard of living; } \\
\text { - environmental quality; } \\
\text { - accessibility for pedestrians and cyclists; } \\
\text { - the distance between related residential } \\
\text { - } \text { and economic areas; } \\
\text { - quality of public transport services; } \\
\text { (maintenance, safety); } \\
\text { - car-sharing, bicycle using, , etc. }\end{array}$ \\
\hline
\end{tabular}

Source: [4] 
Density $(\mathrm{k})$ is defined as the number of vehicles per unit length of the roadway. Inverse of density is spacing (s), which is the center-to-center distance between two vehicles. Traffic volume or flow $(q)$ is the number of vehicles passing a reference point per unit of time, vehicles per hour. The inverse of flow is headway $(h)$, which is the time that elapses between the $i$-th vehicle passing a reference point in space and the $(i+1)$-th vehicle. In congestion, $h$ remains constant.

We assume that the road capacity (or traffic volume) $q$ can be expressed as a time period in proportion to the sum of the length of vehicles and the distance between those vehicles. Neglecting the length of the vehicle, the hourly capacity (hourly traffic volume) can be expressed as [6]

$q=\frac{3600}{h}$, for $h=2 s$ it is $q=1800$ [cars/hour].

This safety distance is given as time reserve expressing reaction time of the driver. However, in order to have a realistic model it is necessary to take into account the nonzero length of the vehicle together with the length of distance between the two vehicles. The common practice to analyze mixed traffic flow is to convert all vehicles into equivalent numbers of passenger car units (PCUs) which correspond to the PCU length of 4-5 meters [7]. At the speed $v$ we can describe in simple relation the length (distance) of vehicles [8]

$d=d_{\min }+v h$.

Density is subsequently the inverse of vehicle distances according to

$k(v)=\frac{1}{d_{\min }+v h}$.

After transferring to the opposite relation velocity dependence on density is obtained according to

$k(v)=\frac{1}{h}\left(\frac{1}{k}-d_{\min }\right)$.

To express the intensity depending on the density we obtain a linear progression

$q(k)=v(k) \cdot k=\frac{1}{h}\left(1-d_{\min } k\right)$.

\section{Measurements of traffic volumes on specific urban roads}

Urban traffic clearly is not a static phenomenon. The authors have dealt with determining traffic patterns typical for selected specific areas within the city. Therefore, the theory of traffic flow is addressed marginally in the next chapters and outputs from the traffic measurement only refer to traffic flow volumes (intensities).

\subsection{Determination of traffic patterns on urban roads}

The series of long-term traffic measurement was carried out on the selected roads within the city using the automatic measurement devices Sierzega SR4 - Fig. 1. The traffic volumes collected by the measurement devices Sierzega SR4 vary both in time and in space [9].

For such traffic survey the specific road sections were selected according to the spatial plan of the city, where the city areas are categorized. Only few categories of function areas within the city were selected to demonstrate the outputs in this paper [10]:

Residential area - the urban road within the residential area was selected with the assumption of minimal share of transit traffic.

Commercial area - the driveway to the commercial zone (shopping centers) was selected.

Industry area - the urban road within the industry zone (logistics centers and warehouses, production halls, etc.) was selected with the assumption of minimal share of transit traffic.

Administrative center - the driveway to the administrative center (in this case it was a university campus) was selected.

Traffic survey was conducted continuously for five working days in a week to get relevant data about traffic flow on the selected urban roads. Data were obtained in October 2016 in the city of Ceske Budejovice.

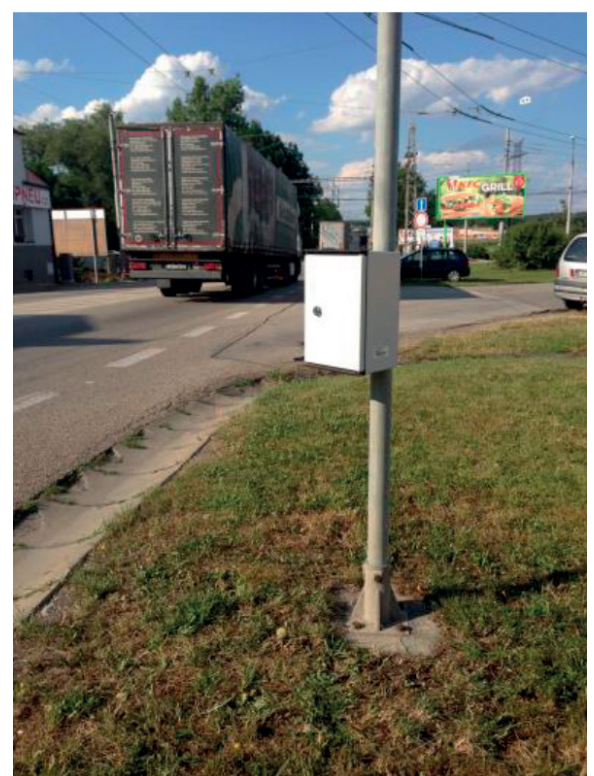

Fig. 1 Sierzega SR4 device mounted on the post of road sign-suitable for long-term measurements (source: Authors) 


\subsection{Evaluation of the traffic volume measurements}

The numbers of vehicles obtained from traffic survey were divided into hourly intervals within all 5 working days and the values were averaged. Traffic flow (and its volume) was divided into both direction to the area and direction from the area to see the differences in daily course of traffic volume. Each hourly interval is expressed as a percentage and represents the share on total average daily traffic volume (100\%). This procedure was used for creating the graphs demonstrating the time course of the traffic volumes within the average working day [11]

Daily course (averaged working day) of traffic volumes obtained from the long-term traffic survey on the road section within the residential area is shown in Fig. 2. The selection of the road section for conducting the traffic survey was done due to the fact that there is a minimal share of transit traffic - the maximum number of vehicles should start or/and end in this area. From the following figure it is evident that the function of the area is predominantly residential, thus we can say the hypothesis of minimal transit traffic share is right. The morning peak hour is mostly given by traffic flow heading from the residential area, on the contrary, the afternoon peak hour is given mostly by traffic flow heading to the residential area (residents are coming back to their homes) [12].

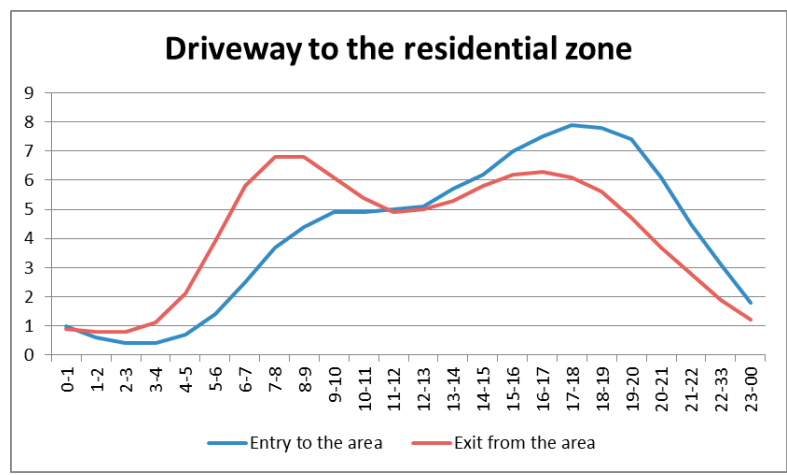

Fig. 2 Daily traffic variations on the road within the residential area - hourly traffic volumes expressed in percentage (source: Authors)

Another selected road section was the driveway to a busy commercial zone. The authors have chosen a commercial zone on the outskirts of the city with plenty of malls and stores and with two driveways only. Daily variations of traffic volumes determined on one of the driveway are shown in Fig. 3.

The infrastructure nearby the shopping centers has mostly the function of access roads. Traffic to shopping centers is associated with their opening hours. Two smooth traffic peaks during a day are generated, on the contrary, in the midnight and early morning hours the traffic is almost none.

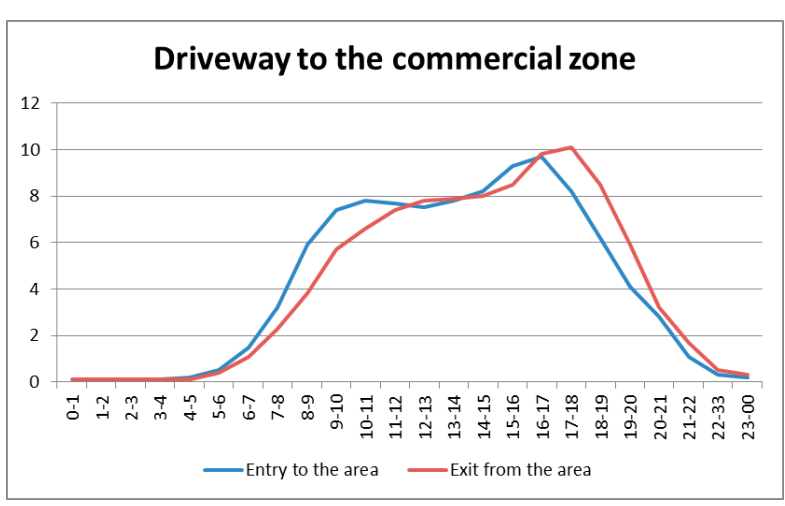

Fig. 3 Daily traffic variations on the road within the commercial area

- hourly traffic volumes expressed in percentage (source: Authors)

Figure 4 shows daily variations of traffic volume on the road within the industry area. The road was selected in a nearly homogeneous area with production halls and warehouses only. The transit traffic on the road is insignificant (up to $10 \%$ ). During evaluation of traffic survey it was necessary to discriminate the category of passenger cars and the category of duty trucks (with maximum permissible laden weight more than 3.5 tons) because the share of heavy vehicles was significant (almost $50 \%$ of all counted vehicles).

Again the traffic on the road reflects the local function of the area. It is evident especially on the hourly shares of passenger cars with the maximum numbers of passenger cars being counted near the beginning of every shift in the main production halls and factories in the area.

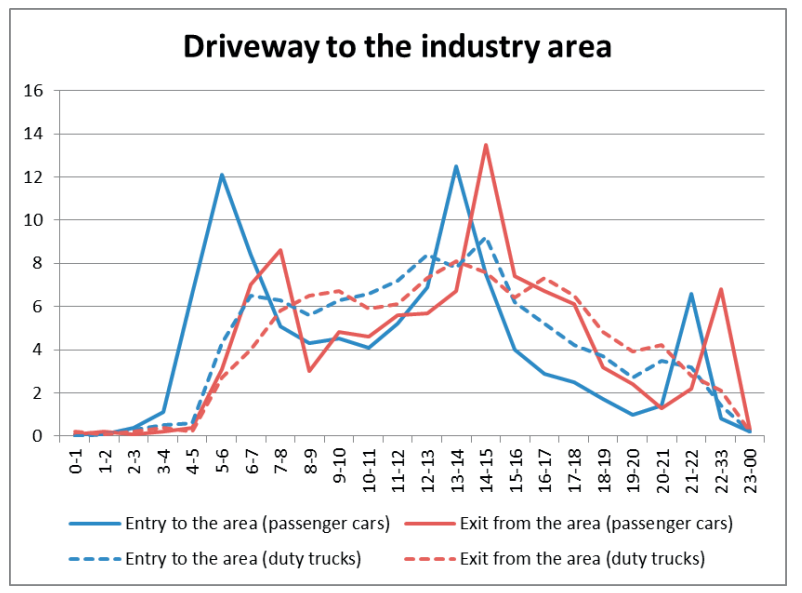

Fig. 4 Daily traffic variations on the road within the industry area - hourly traffic volumes expressed in percentage (source: Authors)

The last selected road section is the driveway to the Institute of Technology and Business in Ceske Budejovice. It is the only access road to the area, where the campus with administrative buildings, auditoriums, library, canteen and dormitories is located. The vast majority of vehicles were 
passenger cars and the daily variations of traffic volumes are shown in Fig. 5.

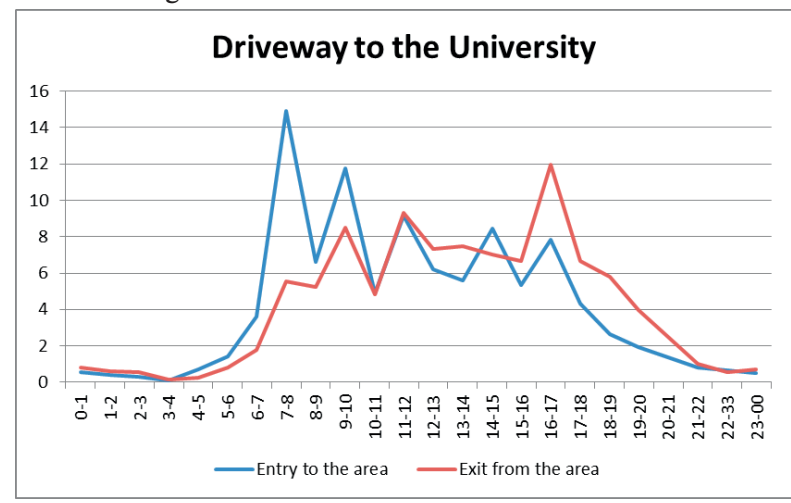

Fig. 5 Daily traffic variations in the University area - hourly traffic volumes expressed in percentage (source: Authors)

\section{Conclusion}

The main objective of the paper was to outline the issue of traffic volume determination, especially the issue of traffic volumes and traffic patterns on the specific urban roads. The authors deal with the theory of traffic flow and evaluate the traffic survey conducted on selected urban roads.

Primary consideration for selecting urban roads for measuring the traffic volume was the fact that roads in the city have different specific traffic pattern (character of traffic) according to the town planning and economic character of the surrounding buildings, for example the daily variations of the traffic intensity will be different for specific urban roads and for the transit fast urban roads with mixed traffic. Daily variation of traffic intensity will also vary with the urban road accessing industrial zones in the city or for urban access roads to schools, student dormitories, administrative institutions etc. We can identify different specific traffic characters (patterns) especially on urban roads, for example [9 and 13]:
- The access roads to shopping centers;

- Urban roads in residential areas;

- Urban roads with administrative centers;

- Fast urban roads;

- Urban roads accessing industrial zones, etc.

When determining the traffic volumes, the methodology according to technical conditions TP 189 is used - The traffic volumes on urban roads are counted from short-time traffic survey according to idea that the traffic flow is the same on a fast urban road within the city as on other urban roads. The important role in the determination of total daily traffic volumes on selected roads has the share of transit traffic. The paper deals with other factors influencing the traffic volumes as well [14 and 15].

The traffic patterns demonstrated in this paper were determined from a short-term traffic survey conducted in the city of Ceske Budejovice by using the automated counting machine Sierzega SR4. The presented traffic patterns are daily traffic variations from Monday to Friday. For detailed conclusions, it is necessary to conduct long-term traffic surveys on which the traffic variations within a week or within the month of a year will be determined. Conducting traffic surveys in other cities of different sizes is also desirable to bring the final determinative conclusions. The authors demonstrated the preliminary outputs of the research of traffic patterns for the purpose of the current methodology update.

\section{Acknowledgement}

The research of traffic flow within the urban areas was partially supported by fund programs National Natural Science Foundation of China (No. 71503011) and Beijing Social Science Foundation of China (No. 16GLC041).

\section{References}

[1] TP 189 Determination of Traffic Volumes on Roads (in Czech), $2^{\text {nd }}$ ed., EDIP s.r.o., 2012.

[2] FGSV (2001) Handbuch fur die Bemessung von Strassenverkehrsanlagen, Forschungsgesellschaft fur Strassen- und Verkehrswesen (in German), FGSV Verlag, Koln.

[3] Czech Republic - Law No.13 / 1997 Sb., "Road Act" (in Czech), as subsequently amended.

[4] MARTOLOS, J., SINDELAROVA, V., BARTOS, L., MUZIK, J.: Methods of Generated Traffic Volume Forecasting (in Czech), EDIP s.r.o., 2013, ISBN 978-80-87394-08-3.

[5] BARTUSKA, L., CEJKA, J., CAHA, Z.: The Application of Mathematical Methods to the Determination of Transport Flows, Nase More, vol. 62, 91-96, 2015

[6] HOlCNER, P., MACUR, J., APELTAUER, T.: Pattern Formation in Traffic Microscopic Model, Traffic and Granular Flow 07, Springer Verlag GmBH, 2007, 249-254, ISBN 3540770739, 


\section{COMMNICOIIIONS}

[7] CHANDRA, S., SIKDAR, P. K.: Factors Affecting PCU in Mixed Traffic Situations on Urban Roads, Road and Transport Research, vol. 9, No. 3, 2000, ProQuest, pp. 40-50.

[8] HOLCNER, P.: Safe Distance between Vehicles and Traffic Flow Simulation (in Czech), Stavebni obzor, published by Faculty of Civil Engineering, CTU in Prague, VUT, VSB, Praha, No. 8, 2009, 251-255, ISSN 1210-4027.

[9] BARTUSKA, L., BIBA, V., KAMPF, R.: Modeling of Daily Traffic Volumes on Urban Roads. Proc. of ICTTE. City Net Scientific Research Center Ltd. Belgrade, 2016, 900-905. ISBN 978-86-916153-3-8.

[10] BARTUSKA, L., STOPKA, O., LIZBETIN, J.: Methodology for Determining the Traffic Volumes on Urban Roads in the Czech Republic. Proc. of the $19^{\text {th }}$ Intern. Scientific Conference on Transport Means, Kaunas: Kaunas University of Technology, 2015, 215-218. ISSN 1822-296X.

[11] GARBER N., HOEL L.: Traffic \& Highway Engineering - SI Version, $4^{\text {th }}$ ed., Cengage Learning, 2009, p. 129. ISBN 9780495438533

[12] OECD, ECMT: Managing Urban Traffic Congestion, Summary Document, 2007, 10-25.

[13] HANZL, J., BARTUSKA, L., ROZHANSKAYA, E., PRUSA, P.: Application of Floyd's Algorithm on Transport Network of South Bohemian Region, Communications - Scientific Letters of the University of Zilina, vol. 18, No. 2, 2016, 68-71.

[14] POLIAK, M., SEMANOVA, S., HERNANDEZ, S., PASTUSZKOVA, E.: Impact of Road Infrastructure Pricing on Transport Planning, Communications - Scientific Letters of the University of Zilina, vol. 17, No. 2, 2015, 92-97.

[15] KOCIANOVA, A.: The Capacity Limits of Roundabouts, Communications - Scientific Letters of the University of Zilina, vol. 16, No. 4, 2014, 81-86. 